\title{
Cheap and easy use of a video laryngoscope as a guide for endotracheal intubation in dogs
}

Ahmed Sabry S. Abdoon ${ }^{1 *}$, Alaaeldin A. Soliman², Said I. Fathalla ${ }^{3}$, Shaban Gadallah ${ }^{4}$, Omaima M. Kandil ${ }^{1}$ and Ashraf H. Shaalan ${ }^{5}$

\begin{abstract}
Background: Tracheal intubation is the second most dangerous procedures reflected in the ICU. It includes passing a plastic tube named endotracheal tube (ET) through the vocal cords into the trachea. Errors of this procedure like the placement of ET in the oesophagus or advancing the ET too far into one of the two lungs are life threatening.

Objectives: This work was designed to provide cheap and quick technique to confirm proper ET tube placement by utilizing simple video laryngoscopy and using dogs as an animal model.

Materials and methods: This study was conducted on 20 dogs divided into two equal group $(n=10)$. The first group, in which a semi-flexible video laryngoscope (VLS) fitted with endotracheal tube was introduced and placed into the trachea of the experimental dogs. In the second group, dogs were intubated through soft and flexible video laryngoscope (VLS) fitted with the endotracheal tube. Number and time of the first attempt for introduction of ET were recorded.
\end{abstract}

Results: The number of attempts was significantly $(P<0.05)$ lower and intubation time was significantly $(P<0.05)$ longer in semi-flexible VLS when compared to soft and flexible video laryngoscope. No complications (death, oesophageal intubation or dental injury) were recorded during the course of the study.

Conclusion: Flexible VLS is more applicable for endotracheal intubation in dogs. It is cheap and can be used for several times without any impairment of its function.

Keywords: Dogs, Video laryngoscope, Endotracheal intubation, Safety

\section{Background}

In dogs and cats, airway obstruction can be life threatening. It may be caused by stenosis, foreign bodies, neoplasia and torsion of the trachea, collapsed tracheal rings, granulomas, external compression or a complication of tracheostomy (Smith et al. 1990). In such case, video laryngoscope (VLS) fitted with endotracheal intubation could provide a simple and practical way for diagnosis and treatment of airway obstruction. Also, endotracheal intubation (ET) delivering inhalation anaesthetic drugs, ensuring a patent airway in unconscious animals, and

\footnotetext{
* Correspondence: assabdoon@yahoo.com

${ }^{1}$ Department of Animal Reproduction and Artificial Insemination, Veterinary Research Division, National Research Centre (NRC), Tahrir St., Dokki, Cairo 12622, Egypt

Full list of author information is available at the end of the article
}

administering oxygen to provide ventilator support in dogs (Cy 2007). In the human, airway management in intensive care unit (ICU) patients is challenging. Hypoxemia is common in patients in the ICU requiring intubation. ET, in which a tube named endotracheal tube passing through the larynx into the trachea, must be performed rapidly to provide mechanical ventilation (Jaber et al. 2006). The clinically accepted position for these tubes is in the middle of the trachea. However, ET in the ICU still carries higher morbidity and mortality rates compared with intubation in the operating room (Griesdale et al. 2008). Most common error that may be encountered during this procedure is the placement of the tube either in the oesophagus or in one of the two lungs. Failure of endotracheal intubation may result in dental damage, laryngeal spasm and bronchospasm, bleeding 
from the upper airway, hypoxia, hypercarbia, regurgitation/ vomiting, various dysrhythmias, cardiac arrest, brain damage or even fatalities (Gupta and Swetha 2016). Video laryngoscopes that use digital and/or optic fibre technology have been designed to improve visibility by direct visualization of the larynx when airway difficulty is predicted or encountered. It also immediately confirms the proper ET placement by seeing the tracheal cartilage rings and proper location of the tip of the ET in the middle of the trachea. VLS is frequently indicated in situations such as heavy sedation like general anaesthesia, in critically injured cases as in bilateral mandibular fractures (Tabrizi et al. 2018), the presence of acute cervical spine injury (CSI) (Holmes et al. 2018) or ill patients to facilitate ventilation of the lungs, including mechanical ventilation, and to prevent the possibility of asphyxiation or airway obstruction. Video laryngoscopes allow a wider viewing angle and make alignment of the oral, pharyngeal and tracheal axes unnecessary (Redel et al. 2009).

Several types of VLS have been introduced into clinical practice and are now available all over the world like McGrath $^{\circ}$ (Campbell et al. 2016), Glidescope ${ }^{\circ}$, Airtraq ${ }^{\circ}$ (Hoshijima et al. 2018), Kingsvision ${ }^{\circ}$, Truview EVO2 ${ }^{\circ}$, $\mathrm{CMAC}^{\circ}$, Pentax ${ }^{\circ}$ and VT-A $100^{\circ}$. Moreover, their ease of use, short learning curves (Kaplan et al 2002; Savoldelli et al 2009) and flexibility make them potential substitutes for conventional direct laryngoscopy (Low et al. 2008; You et al. 2009). However, the higher price, coupled with the high economic recession is leading to the slower adoption of the more expensive VLS. The prices are much higher (e.g., $\$ 6500$ to $\$ 7000$ for the GlideScope) than for a standard laryngoscope (Gao et al. 2018). Therefore, this study was proposed to develop a very low cost model of VLS fitted with endotracheal intubation, which can provide proper endotracheal intubation by seeing the tracheal cartilage rings, and proper location of the tip of the ET in the trachea using dogs as an animal model.

\section{Material and methods}

This work was conducted on 20 normal and healthy mature male Baladi dogs ( $2-3$ years old, and $13.88+0.78 \mathrm{~kg}$ body weight) of no previous history of endotracheal intubation were used in the present study. Animals were kept at Faculty of Veterinary Medicine, Sadat City University. The study was approved by the Ethical Committee of Faculty of Veterinary Medicine, Sadat City University. The experiments were performed in accordance with the recommendations of the National Institute of Health Guide for Care and Use of Laboratory Animals (publication no. 85-23, revised 1985).

Animals were starved for $24 \mathrm{~h}$ before endotracheal intubation. On the day of operation, dogs were given $4 \mathrm{mg} /$ $\mathrm{kg}$ body weight atropine sulphate followed by $1 \mathrm{mg} / \mathrm{kg}$ body weight Zylaject for sedation (Adwaia Com., Egypt) followed by general anaesthesia using intravenous injection of $7.5 \mathrm{mg}$ Thiopental/kg body weight. Following anaesthesia, the dog was placed on a surgical table, lying on the back. X-ray image was taken for the neck and thorax to measure the length of the dog's trachea. Video laryngoscope (Depstech Endoscope 8898, Shenzhen, China) with cold optic fibre light was fitted with endotracheal intubation. In this work, two different size cold optic fibre probes were used for visualization. In the first group $(n=$ 10 dogs), the cold optic fibre was $98 \mathrm{~cm}$ in length and $7 \mathrm{~mm}$ in diameter (semi-flexible, Fig. 1a), and in the second group ( $n=10 \mathrm{dogs}$ ), the cold optic fibre was $198 \mathrm{~cm}$ in length and $4 \mathrm{~mm}$ in diameter (Flexible, Fig. 1b). In both groups, the cold optic fibre probe was introduced into the ET (Sheridan $8.5 \mathrm{~mm}$ cuffed endotracheal tube, Jorgensen Laboratories Inc., Colorado, USA) till $0.2 \mathrm{~cm}$ before its tip (Fig. 2). The ET and VLS
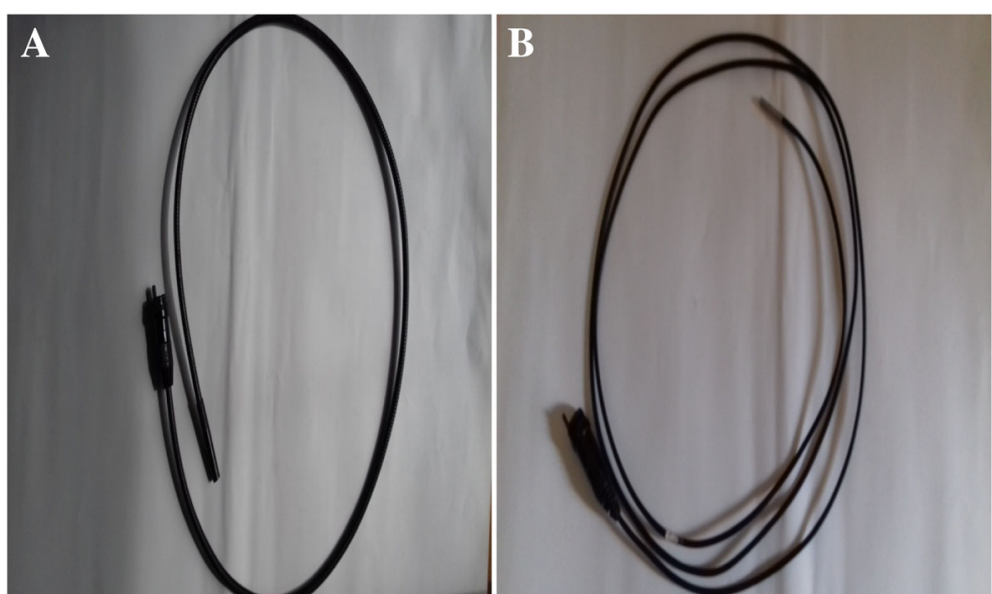

Fig. 1 Photograph showing the semi-flexible (a) and flexible cold fibre probe (b) used as video laryngoscope during endotracheal intubation in dogs 


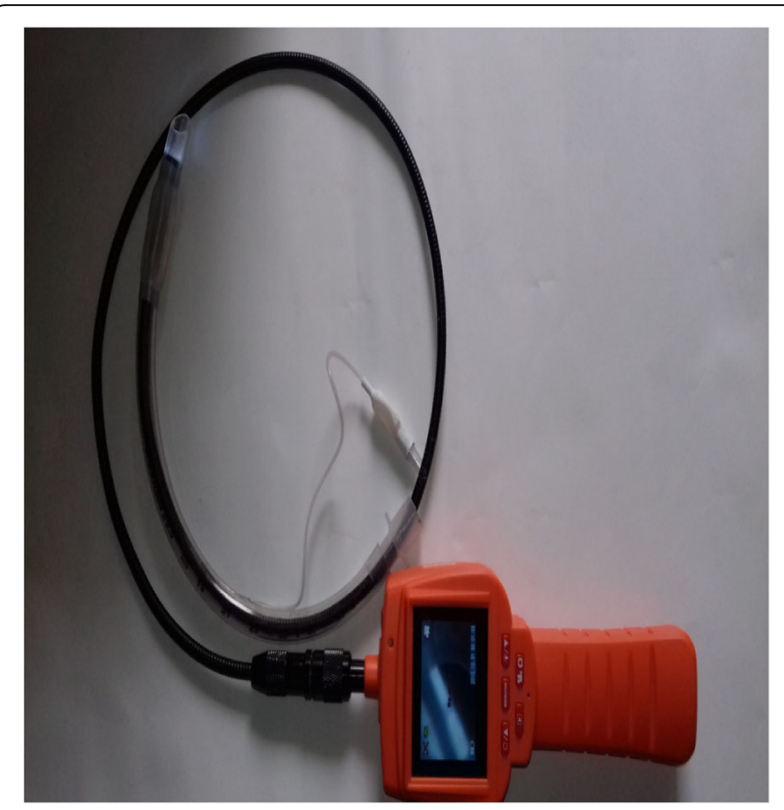

Fig. 2 Photograph for semi-flexible cold fibre optic probe fitted to the endotracheal tube and attached to portable video camera

were introduced through the vocal cords into the trachea of the sedated dog. Visualization of the tracheal cartilage rings was documented in a picture (Fig. 3a). The ET was advanced till the tracheal bifurcation (carina, Fig. 3b) and then proceeds to one of the tracheal bifurcations (Fig. 4). The ET was pulled back to a distance that equals half of the tracheal length. A second X-ray imaging study of the dog's trachea was taken to confirm the placement of the ET and VLS in the middle of trachea (Fig. 5).

Each introduction of the VLS fitted with ET into the oral cavity, then through the vocal cord was considered a separate laryngoscopy attempt. First-pass success was defined as the successful placement of a VLS fitted with endotracheal tube on the first intubation attempt. If the first-pass intubation attempt failed, repeat laryngoscopy was performed. Time from the introduction of the ET +
VLS to its placement in the final proper position was recorded. Animals were checked during the study for complications (death, esophageal intubation, or dental injury).

\section{Study outcomes}

The primary outcome measure was to find out a cheap and applicable method for video guide endotracheal intubation using an animal model (dogs) and the second one is the first-pass success. Other outcomes included (1) the overall intubation success (the proportion of dogs with successful intubation within three attempts), (2) total time to successful intubation and (3) complications (death, esophageal intubation or dental injury).

\section{Statistical analysis}

Data were statistically analysed using STATS2 software.

\section{Results}

The effect of cold optic fibre probe (semi-flexible vs. flexible) on the success rate, time of endotracheal intubation and incidence of complications in dogs is presented in Table 1 . In the current work, a very efficient ET with VLS system was developed and it cost $\$ 25$ to 65 and can be used multiple times with the same efficiency. Seven out of ten dogs $(70 \%)$ in group 1 (in which a semi-flexible cold optic fibre probe was used). In group 2 , in which the flexible cold optic fibre probe was used, ten animals (100\%) were successfully intubated at the first attempt. The difference was significantly $(P<0.05)$ higher in the second group compared with the first one. Mean intubation time was $132.0 \pm 31.5 \mathrm{~s}$ in group 1 and $54.1 \pm 14.6 \mathrm{~s}$ in group 2 (Table 1). Comparison of the data showed a significant difference between the two groups $(P<0.01)$. For the complications arising during conducting the endotracheal intubation, in both groups none of the examined dogs showed death, esophageal intubation or dental injury (Table 1).
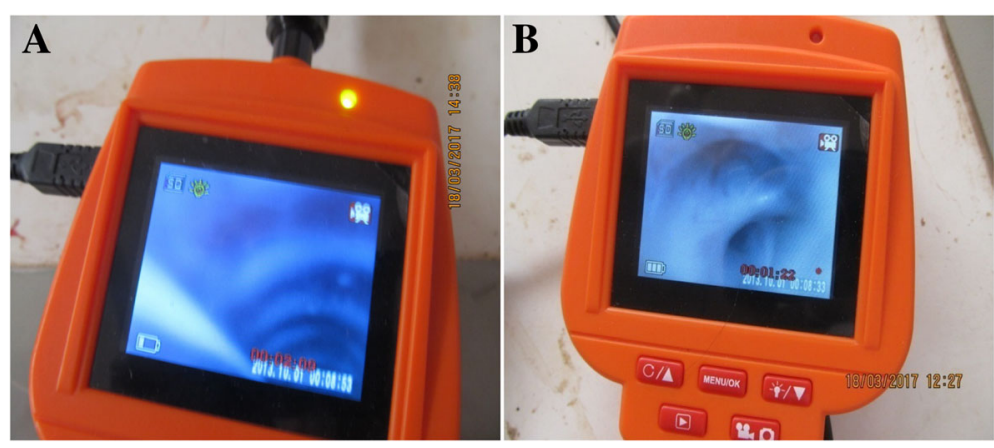

Fig. 3 Endoscopic visualization of the tracheal rings using $V L$ in dogs (a) and the carina (b) 


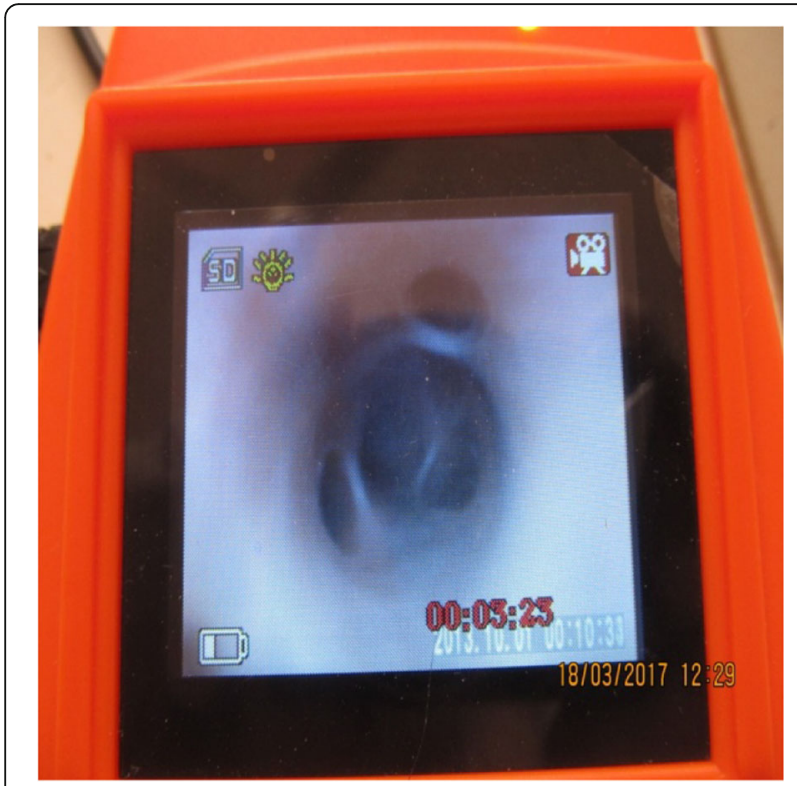

Fig. 4 Endoscopic visualization of one of the tracheal bifurcations showing bronchioles

\section{Discussion}

The purpose of this study was to develop a cheap model for VLS fitted with endotracheal tube that can be used multiple times with the same efficiency. In ICU, many video laryngoscopes are available now in the market; however, the biggest limitation for their use in ICU is their high cost factor particularly for the developing country (e.g. $\$ 6500$ to 7000 for the GlideScope, Gao et al. 2018). In the current work, we developed a

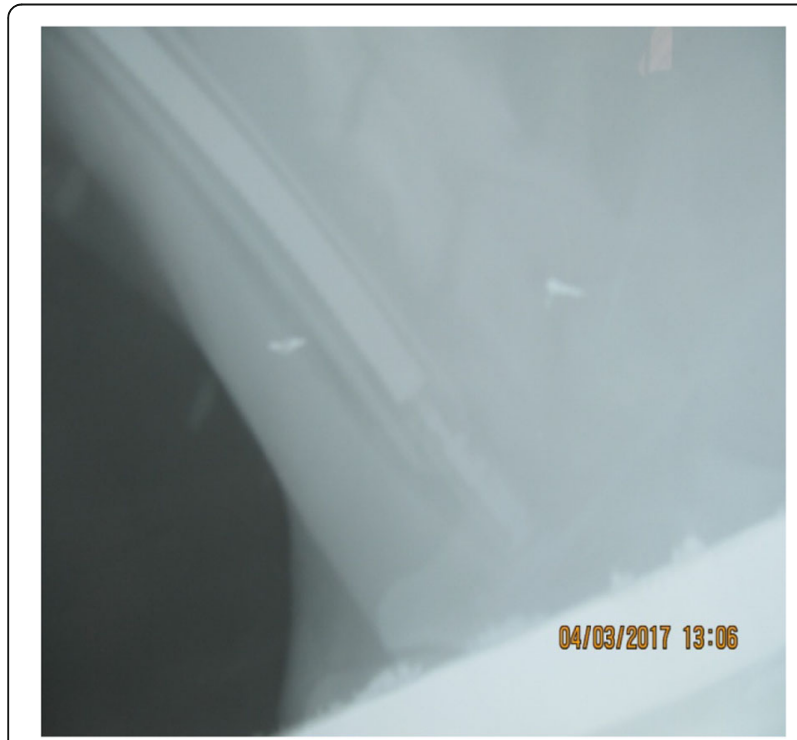

Fig. 5 Lateral cervical radiograph with the endotracheal tube fitted with the semiflexible cold fibre optic probe in the middle of the tracheal lumen
Table 1 Effect of type of cold fibre optic probe on success rate and endotracheal intubation time, and incidence of complications in dogs

\begin{tabular}{lllc}
\hline Item & \multicolumn{3}{l}{ Cold fibre optic probe (\%) } \\
\cline { 2 - 4 } & Flexible & Semiflexible & $P<$ value \\
\hline First intubation success rate & $10 / 10(100)^{\mathrm{a}}$ & $7 / 10(70)^{\mathrm{b}}$ & 0.05 \\
Intubation time/sec & $54.1 \pm 14.6^{\mathrm{c}}$ & $132 \pm 31.5^{\mathrm{d}}$ & 0.01 \\
Complications & 0.0 & 0.0 & \\
\hline
\end{tabular}

a,b Within the same row differ significantly at $P<0.05$

c,d Within the same row differ significantly at $P<0.05$

cheap model of VLS fitted with endotracheal tube, and it can be efficiently used for endotracheal intubation in dogs as an animal model for the first time. This system is both cost effective and mimics various available VLs/ optical models in the market. The whole VLS model developed in this work cost $\$ 25$ to 65 and can be used multiple times. It consists of a cold optic fibre probe (either semi-flexible or flexible) with a video camera and fitted to a portable monitor. Similar models were previously developed but were evaluated by using a manikin as a model (Channa 2011; Trivedi 2014).

Furthermore, in the current study, success rate for endotracheal intubation was significantly $(P<0.05)$ higher for the flexible cold optic fibre probe with $4 \mathrm{~mm}$ diameter when compared with the $7 \mathrm{~mm}$ diameter semi-flexible cold optic fibre probe. Moreover, mean intubation time was significantly $(P<0.01)$ shorter in group 2 (soft and flexible cold optic fibre probe) when compared with group 1 (Semi-flexible cold optic fibre probe) $(132.0 \pm 31.5$ and $54.1 \pm 14.6 \mathrm{~s}$ for group 1 and 2, respectively). The narrow probe (group 2) was more easer to pass through the tracheal tube, while in group 1 (7 $\mathrm{mm}$ in diameter optical fibre probe) was somewhat rigid during manipulation. Other studies on VLS have demonstrated slightly longer intubation times compared with direct laryngoscopy of 3-16 s (Enomoto et al. 2008; Sun et al. 2005; Butchart and Young 2010). This discrepancy could be attributed to the variable experiences of practitioners.

In addition, in this work, no complications were recorded during conducting the endotracheal intubation, and none of the examined dogs in both groups showed death, oesophageal intubation or dental injury. Similarly, no complications have been reported following the use of either the C-MAC device or direct laryngoscopy (Aziz et al. 2012). On contrary, pharyngeal injuries has been observed with other video laryngoscopes (Choo et al. 2007; Hirabayashi 2007; Vincent Jr. et al. 2007). This difference could be due to the type of VLS or the case under investigation. 


\section{Conclusion}

Flexible VLS is cheap and can be efficiently used several times without impairment of its function for endotracheal intubation in dogs.

\section{Acknowledgments}

Not applicable.

\section{Authors' contributions}

ASSA and AAS designed the experiment. ASSA and SIF conducted the experimental work. ASSA drafted the manuscript. All authors were involved in scientific discussion, analysis of the data, and revising the manuscript. All authors read and approved the final manuscript.

\section{Funding}

This research work was completely financed by the authors.

\section{Availability of data and materials}

The dataset obtained and analysed from this work were presented at the text and the original data will be available upon request.

\section{Ethics approval and consent to participate}

This work does not contain studies involving human participants, human data or human tissues.

\section{Consent for publication}

Not applicable.

\section{Competing interests}

The authors declare that they have no competing interests.

\section{Author details}

'Department of Animal Reproduction and Artificial Insemination, Veterinary Research Division, National Research Centre (NRC), Tahrir St., Dokki, Cairo 12622, Egypt. ${ }^{2}$ Hospital of Saint Raphael, Hazlet, NJ 07730, USA. ${ }^{3}$ Department of Physiology, Faculty of Veterinary Medicine, Sadat City University, Sadat, Egypt. ${ }^{4}$ Department of Surgery, Faculty of Veterinary Medicine, Sadat City University, Sadat, Egypt. ${ }^{5}$ Department of Anthropology, Medical Division, NRC, Cairo, Egypt.

Received: 9 January 2019 Accepted: 8 August 2019

Published online: 22 August 2019

\section{References}

Aziz M, Dillman D, Fu R, Brambrink AM (2012) Comparative effectiveness of the C-MAC video laryngoscope versus direct laryngoscopy in the setting of the predicted difficult airway. Anesthesiology 116:629-636

Butchart AG, Young P (2010) The learning curve for video laryngoscopy. Anaesthesia 65:1145-1146

Campbell SG, Magee KD, Zed PJ, Froese P, Etsell G, LaPierre A et al (2016) Endtidal capnometry during emergency department procedural sedation and analgesia: a randomized, controlled study. World J Emerg Med 7(1):13-18

Channa AB (2011) Video laryngoscopes. Saudi J Anaesth 5:357-359

Choo MK, Yeo VS, See JJ (2007) Another complication associated with video laryngoscopy. Can J Anaesth 54:322-324

Cy B (2007) Endotracheal intubation in the dog. Clin Tech 36(2):23-24

Enomoto Y, Asai T, Arai T, Kamishima K, Okuda Y (2008) Pentax-AWS, a new video laryngoscope, is more effective than the Macintosh laryngoscope for tracheal intubation in patients with restricted neck movements: a randomized comparative study. Br J Anaesth 100:544-548

Gao Y, Song Y, Gu Z, Zhang J, Chen X, Sun H, Lu Z (2018) Video versus direct laryngoscopy on successful first pass endotracheal intubation in ICU patients. World J Emerg Med 9(2):99-104

Griesdale DE, Bosma TL, Kurth T, Isac G, Chittock DR (2008) Complications of endotracheal intubation in the critically ill. Intensive Care Med 34(10): 1835-1842

Gupta A, Swetha HRJ (2016) Comparison between Macintosh video laryngoscope and McGrath video laryngoscope for endotracheal intubation in neurosurgical patients. J Evid Based Med Healthc 3:1046-1055
Hirabayashi Y (2007) Pharyngeal injury related to GlideScope video laryngoscope. Otolaryngol Head Neck Surg 137:175-176

Holmes MG, Dagal A, Feinstein BA, Joffe AM (2018) Airway management practice in adults with an unstable cervical spine: the Harborview medical center experience. Anesth Analg. https://doi.org/10.1213/ANE.0000000000003374

Hoshijima H, Maruyama K, Mihara T, Mieda T, Shiga T, Nagasaka H (2018) Airtraq ${ }^{\bullet}$ reduces the hemodynamic response to tracheal intubation using singlelumen tubes in adults compared with the Macintosh laryngoscope: a systematic review and meta-analysis of randomized control trials. J Clin Anesth 47:86-94. https://doi.org/10.1016/j.jclinane.2018.03.022

Jaber S, Amraoui J, Lefrant JY, Arich C, Cohendy R, Landreau L et al (2006) Clinical practice and risk factors for immediate complications of endotracheal intubation in the intensive care unit: a prospective, multiple-center study. Crit Care Med 34(9):2355-2361

Kaplan MB, Ward DS, Berci G. A new video laryngoscope: an aid to intubation and teaching. J ClinAnesth 2002; 14:620-626.

Low D, Healy D, Rasburn N (2008) The use of the BERCI DCl video laryngoscope for teaching novices direct laryngoscopy and tracheal intubation. Anaesthesia 63:195-201

Redel A, Karademir F, Schlitterlau A et al (2009) Validation of the glidescope video laryngoscope in pediatric patients. Paediatr Anaesth 19:667-671

Savoldelli GL, Schiffer E, Abegg C, Baeriswyl V, Clergue F, Waeber JL. Learning curves of theGlidescope, the McGrath and the Airtraq laryngoscopes: a manikin study. Eur J Anaesthesiol. 2009;26(7):554-8.

Smith MM, Gourley IM, Arnis TC, Kurpershoek C (1990) Management of tracheal stenosis in a dog. JAVMA 196(6):931-934

Sun DA, Warriner CB, Parsons DG, Klein R, Umedaly HS, Moult M (2005) The GlideScope video laryngoscope: randomized clinical trial in 200 patients. Br J Anaesth 94:381-384

Tabrizi R, Dahi M, Moshari MR, Pourdanesh F, Zolfigol S (2018 . pii: S02782391 (18)30283-0. doi) Video laryngoscopy or Macintosh laryngoscopy: which one is more successful in patients with bilateral mandibular fractures? J Oral Maxillofac Surg. https://doi.org/10.1016/j.joms.2018.03.025

Trivedi JN (2014) An economical model for mastering the art of intubation with different video laryngoscopes. Indian J Anaesthesia 58(4):394-396

Vincent RD Jr, Wimberly MP, Brockwell RC, Magnuson JS (2007) Soft palate perforation during orotracheal intubation facilitatedby the GlideScope video laryngoscope. J Clin Anesth 19:619-621

You JS, Park S, Chung SP et al (2009) The usefulness of the GlideScope video laryngoscope in the education of conventional tracheal intubation for the novice. Emerg Med J 26:109-111

\section{Publisher's Note}

Springer Nature remains neutral with regard to jurisdictional claims in published maps and institutional affiliations.

\section{Submit your manuscript to a SpringerOpen ${ }^{\circ}$ journal and benefit from:}

- Convenient online submission

- Rigorous peer review

- Open access: articles freely available online

- High visibility within the field

- Retaining the copyright to your article

Submit your next manuscript at $\boldsymbol{\nabla}$ springeropen.com 